http://jmscr.igmpublication.org/home/ ISSN (e)-2347-176x ISSN (p) 2455-0450

crossref DOI: https://dx.doi.org/10.18535/jmscr/v9i11.04

Journal Of Medical Science And Clinical Research

\title{
Spring Bridge in Rehabilitation of Kennedy Class 3 Partial Edentulous Situation
}

\author{
Meena Mudgal ${ }^{1}$, George Francis ${ }^{2}$, Pratik Jain ${ }^{2}$, Ramprasad Verma ${ }^{3}$, Jacob John $\mathbf{H}^{4 *}$ \\ ${ }^{1}$ Lecturer, Department of Oral Medicine and Radiology, Government Dental College, KUHS, India \\ ${ }^{2}$ Lecturer, Department of Prosthodontics, Government Dental College, MJPRU, India \\ ${ }^{3}$ Lecturer, Department of Periodontology, CIIDSRC, KUHS, India \\ ${ }^{4 *}$ Assistant Professor, Department Of Prosthodontics, CIIDSRC, KUHS, India \\ *Corresponding Author \\ Jacob John H
}

\begin{abstract}
Rehabilitation of partial edentulous spaces using abutment on either side is one of the ideal treatment in the field of fixed Prosthodontics. Using an abutment that is distant from the missing tooth, has peculiar conditions which have not been much reported in the literature. This article presents a case of an adult male patient whose maxillary right central incisor was missing. The maxillary first premolar on the same side was rotated due to loss of adjacent tooth contact. In order to restore the balance of entire dentition, it was important to restore lost proximal contact of the maxillary first premolar utilizing a full restoration. Using a bar as a spring connector, the crown on the maxillary right premolar served as an abutment to replace the missing central incisor on the same side. This form of bridge is relatively less done in clinical practice. The patient was extremely satisfied with the outcome of the fixed partial denture design.

Keywords: cast restoration, cantilever, fixed partial denture, pontic, retainer.
\end{abstract}

\section{Introduction}

The use of metal, ceramic technology in dentistry dates back to $1970,{ }^{1}$ and still continues to enjoy its dominance despite a plethora of all ceramic materials being investigated to replace the metal. While a full covered metal, ceramic restoration has more influence on periodontal than partial coverage, ${ }^{2}$ it is also important to note that the use of metal allows minimum reduction of tooth structure. Use of partial veneer crowns have been underutilized mainly due to their ability of being just a secondary retainer and the compulsory use of gold containing alloys. 3 Minimal thickness of a restoration influence its self cleansing ability and imparts more strength to the tooth restoration interface.
Restoration of excessively large partial edentulous spaces with a fixed partial denture cannot be done unless there is a change in the connector designs. It has been reported that in such cases various factors that contribute to success include the treatment option selected, the final esthetic outcome, biomechanics involved, durability of restoration and patient satisfaction. ${ }^{4-6}$ Diastema among teeth be it midline or lateral, is a clinical condition that presents itself as a discrepancy between natural teeth and the available ridge. ${ }^{7}$ Since the tooth follows esthetic proportions, the ratio of length to width if altered, looks highly unaesthetic, especially when available background is contrasted with it. 
One of the significant determinant of the design of prosthesis in most of the challenging fixed partial denture cases is the existing occlusion. ${ }^{8}$ Besides the health of stomatognathic system, the occlusion especially the anterior guidance has also been reported to influence the size of the restoration. 8 this article presents a clinical case of a male adult who had undergone endodontic treatment in relation to maxillary right lateral incisor and had an adjacent Kennedy class 3 partial edentulous situation whose mesiodistal dimension was large due to a midline diastema before tooth loss.

\section{Case Report}

A young adult male aged 32 years reported to the Department of Prosthodontics with chief complaint of impaired facial esthetics due to loss of front upper tooth. Patients medical, social, drug and dental history did not significantly impact the existing treatment. Patients extra oral examination revealed a bilaterally symmetrical face with temperomandibular joint and other structures within normal limits. Intra oral examination revealed a large part edentulous that did not cross the midline in the maxillary arch. A diagnostic impression with alginate (Jeltrate Alginate, Fast Set; Dentsply Intl, York, $\mathrm{Pa}$ ) was made for both arches and diagnostic cast was evaluated for mesiodistal space of the partial edentulous area using a diagnostic mounting. Maxillary right first premolar was mesially rotated (palatal side) while there was a slight increase in overjet anteriorly. The option of implant supported single crown was not considered since adjacent teeth required a crown and the cost of the treatment was not affordable for the patient. The design for the fixed partial denture was that of a spring cantilever which would use the maxillary right first premolar as an abutment while replacing the maxillary right central incisor. An individual metal, ceramic crown would also be required for crowning of maxillary right lateral incisor. The spring cantilever would use a bar connector $(3 \mathrm{~mm}$ sprue wax) as recommended in the literature. ${ }^{4}$

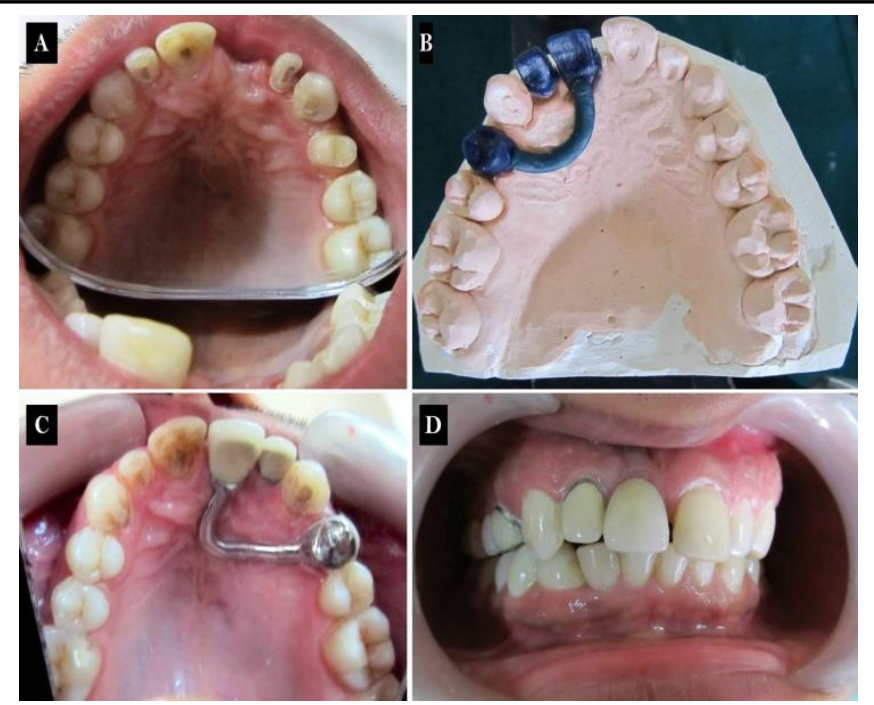

Figure 1: (a) Intra oral view showing prepared teeth (b) Wsx pattern for designed bridge (c) Spring bridge cemented in place (d) Anterior view of spring cantilever bridge

After obtaining the informed consent from the patient, tooth preparation for metal, ceramic retainers was done in relation to maxillary right lateral incisor and first premolar (Fig $1 \mathrm{~A}$ ). This was followed by gingival retraction (Traco; VOCO $\mathrm{GmbH}$, Cuxhaven, Germany) and impression making, using elastomeric impression material (Affinis; Coltene AG, Altstatten; Switzerland). In the laboratory, wax patterns were fabricated using hard inlay wax (Bego,Wilhelm-Herbst, Germany). The connector between the premolar and the Pontic (central incisor) was done as a bar (Sprue wax, Bego,Wilhelm-Herbst, Germany) (Fig 1 B). After processing of the metal framework, the metal and porcelain (VMK-95 Metall Keramik; Vita Zahnfabrik, Bad Sackingen, Germany) trials were done ensuring the rigidity of the connector. After porcelain trial, an overglaze was applied and the entire spring cantilever bridge and an individual crown were cemented using polycarboxylate cement (Poly F Plus; Dentsply DeTrey GmbH, Konstanz, Germany). Occlusal clearance (Fig 1 C) was verified clinically and esthetics were approved by the patient (Fig 1 D). The patient was satisfied with the outcome of the entire bridge design. The patient was put on a follow up protocol and reported to the department for one year without any sign of failure or any complication. 


\section{Discussion}

A case presenting the use of a spring cantilever type of fixed partial denture has been described in this article. The feature of the case being the ideal criteria for indication of such case. Since a cantilever is supported at one end, it is important to analyze certain criteria when one makes a physiologic appraisal for such cases. These include periodontal attachment of abutment, alveolar support, arch relationship and finally occlusal relation. ${ }^{9,10}$ Generally, a cantilever fixed prosthesis is considered to be more successful when placed anteriorly (missing lateral incisor) than posterior replacements. ${ }^{11}$ Two important factors that contributed to the spring cantilever design in this case where the presence of excessive overjet with little overbite and the presence of a rotated first premolar. Patient had a canine protected occlusion and involving canine in the design would have meant to alter the occlusion to group function on that side which was not possible because the guidance wouldn't allow such occlusal scheme. Using the maxillary right first premolar as an abutment allowed correction of the rotated tooth and thus correcting the proximal contact relationship of the collapsing dentition. One of the problems that was anticipated because of excessive overjet was the supra eruption that would occur when teeth are flared. Such problems with excess overjet have been reported in the literature. ${ }^{12,13}$ After one year of evaluation at follow up, there wasn't any significant alteration in the incisal plane of the mandibular anteriors. This could be due to the already tight contacts (overcrowded anteriors) between anterior teeth as a result of less spaces between them. First choice, for correcting the malpositioned or rotated tooth is orthodontics, ${ }^{14}$ which were not approved by the patient because of time and financial constraints. Lateral incisor was endodontically treated and therefore was kept out of the design since the lateral incisor is a weak abutment that was weakened further by endodontic treatment. Mechanical failure of a cantilevered fixed partial denture associated with non vital teeth has been reported by different authors. ${ }^{15,16}$ Since cantilever bridges can be either supported by a single tooth, multiple teeth or a distant tooth, ${ }^{17}$ studies in different parameters need to be conducted as biomechanics involved are different for each type.

Lateral forces may be applied to the tooth if proper occlusal analysis is not done during clinical diagnosis and examination. Protrusive movements although exert less forces on that abutment tooth, but a spring cantilever design should be an exception since the lever arm is long and distant from the pontic.

\section{Conclusion}

Using distant abutment to replace a missing natural tooth should be done keeping existing occlusion and the condition of the abutment in mind. A bar connector is sufficiently rigid enough to inhibit flexing. Spring cantilever fixed partial denture is an excellent treatment choice and should be utilized more frequently.

\section{Acknowledgements}

The authors would like to thank the dental technician of the department for their valued contribution in completion of the case.

\section{Conflict of interest: None}

\section{References}

1. Goswami R, Garg R, Mattoo K. Impact of anterior guidance in designing of Allceramic anterior fixed partial denture - Case Report. Journal of Advanced Medical and Dental Sciences Research 2019;7 (11): 5961.

2. Parai P, Ojah P, Jain S, Khan N, Gangwar S, Mattoo K. A comparative evaluation of the efficacy of two gingival retraction systems: an in vivo study. European Journal of Molecular \& Clinical Medicine, 7, 8, 2021, 4870-4880.

3. Jain K, Mattoo K. Using a partial veneer crown as a conservative retainer in fixed prosthodontics. Medico Research Chronicles 2015;2(2):187-90. 
4. Kumar L, Mattoo K, Goswami R. Spring Fixed Partial Denture Designing. International Journal of Medical Research and Pharmaceutical Sciences 2017; 4 (10):13

5. Henderson D, Blevins WR, Wesley RC, Seward T. The cantilever type of posterior fixed partial dentures: a laboratory study. The Journal of Prosthetic Dentistry. 1970;24(1):47-67.

6. Valderhaug J. Periodontal conditions and carious lesions following the insertion of fixed prostheses: a 10-year follow-up study. International Dental Journal. 1980;30(4):296-304.

7. Mattoo K, Singh M, Goswami R. Resin bonded loop connector fixed partial denture - A subtle solution to maintain midline diastema. International Journal of Dental Sciences and Research 2014; 2(6):168-170

8. Khurshid AM, Garg N. Significance of Anterior Guidance in Selection of Posterior Teeth. Open Access Journal of Dental Sciences 2017, 2(5): 000148

9. Sharma A, Rahul GR, Poduval ST, Shetty K. Assessment of various factors for feasibility of fixed cantilever bridge: a review study. ISRN Dent. 2012;2012:259891.

10. Mattoo KA, Mahajan P. Role of overjet and overbite fixed partial denture aesthetics. EAS J Dent Oral Med 2020; 2(2): 52-54

11. Himmel R, Pilo R, Assif D, Aviv I. The cantilever fixed partial denture - a literature review. The Journal of Prosthetic Dentistry. 1992;67(4):484-487.

12. Gohal MRA, Mattoo KA, Nazish A, Youseef AM. Corrective Prosthodontics Curating Semi Functional Anterior Guidance in Full Mouth Rehabilitation: Case Report. Journal of Medical Science and Clinical Research 2017;5(08):26777-781.

13. Lundgren D, Laurell L. Occlusal force pattern during chewing and biting in dentitions restored with fixed bridges of cross-arch extension. II. Unilateral posterior two-unit cantilevers. Journal of Oral Rehabilitation. 1986;13(2):191-203.

14. Yadav L, Mattoo KA, Kapoor A, Shuja S. Factors associated with post core correction of malpositioned teeth. International Journal of Research in Medical Sciences and Technology 2015;1(2):5-7

15. Wright WE. Success with the cantilever fixed partial denture. The Journal of Prosthetic Dentistry. 1986;55(5):537-539.

16. Landolt A, Lang NP. Results and failures in extension bridges. A clinical and roentgenological follow-up study of free-end bridges. Schweizer Monatsschrift fur Zahnmedizin. 1988;98(3):239-244.

17. Brar A, Mattoo K, Jain P. Designing Cantilever Prosthesis: A Case Study. (Research \& Reviews: A Journal of Dentistry ) RRJoD 2014;5(3): 5-9 